\title{
Degree of Frugivory Predicts Rates of Food-Related Agonism and Intragroup Proximity in Wild Gray Woolly Monkeys (Lagothrix lagotricha cana)
}

\author{
Thiago Cavalcante ${ }^{1,2}$ (D) Karen B. Strier ${ }^{3}$. Júlio César Bicca-Marques ${ }^{2}$
}

Received: 3 September 2020 / Accepted: 30 March 2021/ Published online: 22 May 2021

(C) The Author(s), under exclusive licence to Springer Science+Business Media, LLC, part of Springer Nature 2021

\begin{abstract}
The main factors influencing feeding competition among members of diurnal primate groups are the distribution, availability, and quality of food resources. Socioecological models predict that temporal availability of preferred resources, such as fruit, can influence intragroup feeding competition, which is expected to affect rates of agonism and intragroup spatial patterns. We evaluated the effects of temporal variation in fruit availability on the degree of frugivory (i.e., the proportion of time spent feeding on fruit in relation to total food consumption) and the effects of fruit availability and degree of frugivory on rates of agonistic interactions, and intragroup proximity in two wild groups of gray woolly monkeys (Lagothrix lagotricha cana) in southwestern Brazilian Amazonia. We recorded 227 agonistic interactions via the all occurrences method and 3549 records of spacing via scan sampling during an 8-mo field study from March to October 2017. We found that fruit availability showed a positive relationship with the woolly monkeys' degree of frugivory, which in turn showed a positive relationship with the rates of agonism. We also found that degree of frugivory positively affected intragroup proximity in periods of lower fruit availability, and that agonistic interactions and proximity covaried positively. Conversely, as the degree of frugivory increased, monkeys exhibited greater interindividual distances and, consequently, lower rates of agonism, consistent with lower levels of feeding competition in periods of higher fruit availability. Therefore, we suggest that intragroup contest competition for fruits is an important cost of group living even for generalized, opportunistic frugivorous primates, such as woolly monkeys.
\end{abstract}

Keywords Feeding behavior · Fruit availability · Interindividual distance · Intragroup feeding competition $\cdot$ Socioecology

Handling Editor: Joanna Setchell.

Thiago Cavalcante

thiagocav.ferreira@gmail.com

Extended author information available on the last page of the article 


\section{Introduction}

Feeding competition among members of diurnal primate groups is influenced mainly by the distribution, density, and quality of food resources (Isbell 1991; Wrangham, 1980). Socioecological models predict intragroup contest competition will be greatest when high-quality foods, such as fruit, are seasonally scarce and patchily distributed (Isbell 1991; Snaith and Chapman 2007). However, if large patches of food resources are evenly distributed, intragroup scramble competition will be the major process structuring intragroup feeding relationships (Snaith and Chapman 2007).

The avoidance or reduction of intragroup feeding competition over access to highquality food consequently becomes a major challenge for group-living primates (Isbell, 1991; Isbell et al. 1998; Majolo et al. 2008; Wrangham, 1980). For example, when fruit is scarce and spatially clumped, several individuals can feed closely in a patch of neighboring trees. Although such close proximity can reduce the individual risk of predation (e.g., Boinski et al. 2000; Fairbanks and Bird 1978), it can increase feeding competition and the frequency of agonistic interactions (Bernstein 2007; Pereira 1988; $\mathrm{Su}$ and Birky 2007). Under these conditions, groups may split up into temporary subgroups or parties, a behavioral strategy known as fission and fusion (Aureli et al. 2008). This strategy is typically employed by fruit specialists such as spider monkeys (e.g., Ateles chamek and A. geoffroyi: Chapman et al. 1995; Symington, 1990), bearded sakis (e.g., Chiropotes satanas: Norconk and Kinzey 1994), and chimpanzees (Pan troglodytes: Chapman et al. 1995; Symington 1990).

For frugivorous primates with more eclectic diets, variation in grouping patterns can be attributed to variation in the availability of their preferred fruit sources. When fruits are seasonally scarce, they can shift their diets to include less preferred resources such as leaves, flowers, arthropods, and even small vertebrates (Cavalcante et al. 2019; Di Fiore and Campbell 2007; Gonzalez et al. 2016; Peres 1994a; Stevenson et al. 1994). For example, a small cohesive group of 24 common woolly monkeys (Lagothrix lagotricha) devoted up to $84 \%$ of its feeding time to fruit and $5 \%$ to arthropods at the Caparú Biological Station, eastern Colombia (Defler, 1996). However, a larger group of up to 40 individuals at the same site was less frugivorous, sustaining diets of only up to $69 \%$ fruit, while arthropods represented $13 \%$ of the group's diet (Gonzalez et al. 2016).

High variation in degree of frugivory can lead to correspondingly high variation in rates of agonism among group members and in intragroup proximity (Robbins 2008; Stevenson et al. 1994). For example, agonistic interactions can be more frequent in fruit feeding contexts (i.e., within a fruiting tree) than in nonfeeding contexts (Di Fiore and Fleischer 2005; Robbins 2008; Stevenson et al. 1994). This pattern is at least partially explained by the greater intragroup proximity during fruit consumption than when exploiting other food items such as arthropods and leaves (Robbins 2008; Stevenson et al. 1998). Additionally, the total number of agonistic interactions and the number of interactions that occurred while feeding on fruit can be higher during periods of higher fruit availability (e.g., Stevenson et al. 1994). This monotonic positive pattern is found, for example, in mountain gorillas (Gorilla beringei), white-faced capuchin monkeys (Cebus capucinus), and common woolly monkeys, and is compatible with the hypothesis that intragroup agonistic feeding competition increases over high-quality monopolizable resources (Robbins 2008; Stevenson et al. 1994; Vogel and Janson 2007). 
In contrast, periods of greater frugivory can occur when there is plenty of fruit to satiate all or most group members. Under these conditions, rates of agonism should decrease as fruit availability increases. However, rates of agonism can also decline if group members avoid close proximity with one another during times of high fruit availability. In these cases, low rates of agonism could be a function of spacing patterns more than of satiety because the foragers can spread out over greater distances when exploiting several food patches in periods of higher fruit abundance/consumption (e.g., Lins and Ferreira 2019). Therefore, to improve our understanding of intragroup feeding competition, examining changes in feeding-related behaviors such as agonism and intragroup proximity in response to degree of frugivory needs to consider the indirect effect of fruit availability to allow a stronger evaluation of the possible outcomes.

In this study we assessed the effects of temporal variation in fruit availability on the degree of frugivory (i.e., the proportion of time spent feeding on fruit in relation to total food consumption) of gray woolly monkeys (Lagothrix lagotricha cana) in the southwestern Brazilian Amazonia. We also assessed if the study groups preferred large fruit patches. Lastly, we assessed the effects of fruit availability and degree of frugivory on their rates of intragroup agonistic interactions (as a proxy for intragroup contest competition), and interindividual spacing behavior. Specifically, we tested four main hypotheses derived from basic socioecological models of intragroup feeding competition:

H1: If gray woolly monkeys in southwestern Brazilian Amazonia behave as generalized opportunistic frugivorous, similar to other woolly monkey populations (Gonzalez et al. 2016), we predicted that the degree of frugivory would increase with increasing fruit availability (Gonzalez et al. 2016; Peres 1994a; Stevenson, 2004).

H2: If intragroup contest competition increases over access to preferred highquality foods such as fruit (Robbins 2008; Stevenson et al. 1994; Vogel and Janson 2007), we predicted that the rates of agonistic interaction among wild gray woolly monkeys would be associated with fruit availability and/or the degree of frugivory.

H3: If the fruits exploited by gray woolly monkeys are more clumped than most of their other types of food as reported for other frugivorous primates (Isbell 1991; Isbell et al. 1998; Wrangham, 1980), we predicted that the relationship between degree of frugivory and intragroup proximity would depend on fruit availability. H4: Finally, if intragroup proximity affects the pattern of intragroup feeding competition (Bernstein 2007; Pereira 1988; Su and Birky 2007), we predicted that rates of agonism and proximity would significantly covary.

\section{Methods}

\section{Study Sites and Subjects}

TC collected all data in two fragments of Amazonian forest (A: $11^{\circ} 19^{\prime} 12.46^{\prime \prime} \mathrm{S}, 61^{\circ} 25^{\prime}$ $33.84^{\prime \prime} \mathrm{W}, c a .120$ ha; B: $11^{\circ} 28^{\prime} 24.35^{\prime \prime} \mathrm{S}, 61^{\circ} 21^{\prime} 21.10^{\prime \prime} \mathrm{W}, c a .400$ ha; each $c a .186 \mathrm{~m}$ a.s.1.) in Cacoal, State of Rondônia, Brazil (Fig. 1). The climate is rainy tropical (Aw in 

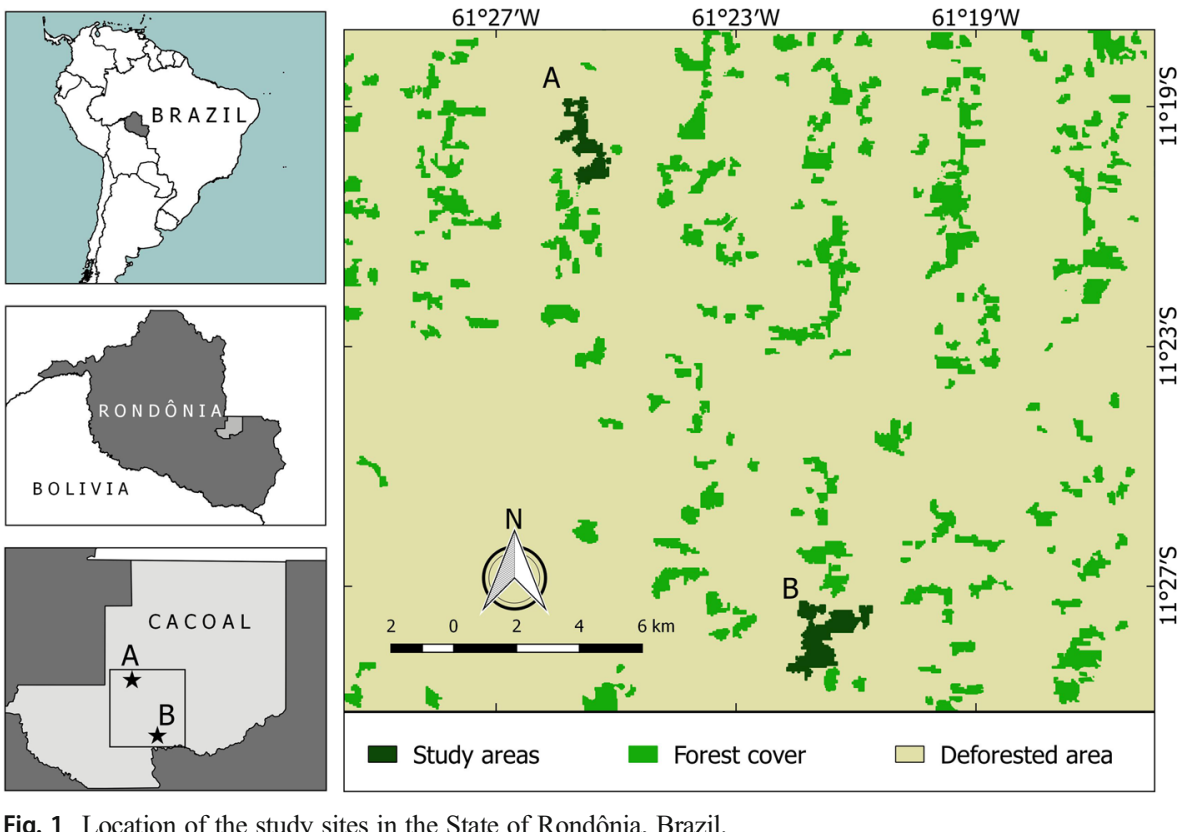

Fig. 1 Location of the study sites in the State of Rondônia, Brazil.

Köppen's classification), with mean annual average temperature of $25.6^{\circ} \mathrm{C}$. The highest mean monthly average temperature of $35.2^{\circ} \mathrm{C}$ is in September and the lowest mean monthly average of $21.1^{\circ} \mathrm{C}$ occurs in July. The mean relative humidity is $75 \%$, ranging from $60 \%$ in August to $89 \%$ in February. Mean annual rainfall is $1760 \mathrm{~mm}$, with monthly means of $251 \mathrm{~mm}$ during the rainy season (October-March) and of $39 \mathrm{~mm}$ during the dry season (April-September) (1998-2010, Boletim Climatológico de Rondônia - 2010; SEDAM 2012).

Ten primate species are found at both study sites (Cavalcante et al. 2018; Iwanaga and Ferrari 2001): gray woolly monkeys, black-faced black spider monkeys (Ateles chamek), Purús red howler monkeys (Alouatta puruensis), brown capuchin monkeys (Sapajus apella), bare-eared squirrel monkeys (Saimiri ustus), Prince Bernhard's titi monkeys (Plecturocebus bernhardi), red-nosed cuxiús (Chiropotes albinasus), Mittermeier's Tapajós saki (Pithecia mittermeieri), black-headed marmosets (Mico nigriceps), and black-headed night monkeys (Aotus nigriceps).

It was not possible to determine the exact size and composition of either of the Lagothrix groups because individuals could not be recognized. However, subgroups consisted of 1 to $20+$ individuals, frequently comprised from 3 to 5 adult males and of $5+$ females and immatures. We may have underestimated subgroup size due to their wide interindividual spacing, as has also been observed in other populations of gray woolly monkeys (Peres 1996).

\section{Behavioral Sampling}

We recorded behavioral data from March to October 2017. We divided the study into 20 sampling periods, alternating between sites for a total of 10 sampling periods per site. Each sampling period spanned a maximum of 10 days and consisted of 3 days of 
behavioral sampling, followed by phenological sampling. We obtained a total of $617 \mathrm{~h}$ of behavioral observations (group $A=313 \mathrm{~h}$; group $\mathrm{B}=304 \mathrm{~h}$ ). We recorded data on activity, diet composition, and proximity during 5-min scan samples (Altmann 1974) conducted at 30-min intervals between sunrise and sunset. We obtained a total of 3549 scan samples with an average of 5 individuals per sample (range: 1-14 individuals).

For each individual in each scan sample, we recorded the activity (resting, feeding, traveling, socializing, and other behaviors, which included drinking, scent marking, exploring, and suckling), and the distance to the nearest neighbor(s). Obstruction of view by dense forest canopy prevented us from reliably determining interindividual spacing in $13 \%$ of the behavioral records $(N=458)$, which were assigned as not available (NA), and excluded from further analyses. Therefore, we only analyzed data recorded under conditions of adequate visibility for estimating the interindividual distance. Although the representativeness of these NA records ranged from $3 \%$ to $41 \%$ of the daily records $($ mean $=14 \% \pm$ SD 9\%, median $=12 \%)$, in only 8 of the 58 sampling days they accounted for $>20 \%$ of the records. Additionally, NA records were well distributed among the activities (resting: 3\%; feeding: 4\%; traveling: 4\%; socializing: 1\%). Therefore, we do not believe that the exclusion of NA records has biased the results.

We recorded 1128 feeding events, of which $90 \%(N=1017)$ could be distinguished by item. These included ripe or unripe fruit, flower or flower bud, new or mature leaf, vertebrate or invertebrate prey, and other. We excluded 111 feeding records (10\%) that we could not distinguish by item from the analyses.

We recorded agonistic interactions $(N=227)$ via all occurrences sampling. Agonistic interactions consisted of supplants, chases, grips, bites, and other aggressive physical contacts (Di Fiore and Fleischer 2005; Ramirez 1988). We may have underestimated the frequency of supplants because they are silent and therefore more prone to go undetected in less visible parts of the canopy. We also classified aggressive interactions into feeding-related and non-feeding-related contexts. We could not determine the context in $15 \%$ of the cases $(N=79)$ or the contested resource in $35 \%$ of the aggressive interactions $(N=34)$. We used all feeding-related agonistic interactions to calculate the rates of agonism.

\section{Phenological Sampling}

We established 12 transects of $250 \mathrm{~m} \times 10 \mathrm{~m}$ to monitor tree phenology in the study sites (Gentry 1982; Magnusson et al. 2005): 5 transects in study site A (1.25 ha total) and 7 in study site $\mathrm{B}$ (1.75 ha total). We marked and measured all trees with diameter at breast height $(\mathrm{DBH}) \geq 10 \mathrm{~cm}$ (Di Fiore 2003; Peres 1994a) (site A: mean DBH $=21 \pm$ $\mathrm{SD} 13 \mathrm{~cm}, N=492$; site B: mean $\mathrm{DBH}=25 \pm \mathrm{SD} 26 \mathrm{~cm}, N=781)$. We randomly selected 300 trees for phenological monitoring in each fragment. We used binoculars $(10 \times 42)$ to evaluate the presence of fruit in the tree canopies. Tree death during the study $(\mathrm{A}=12, \mathrm{~B}=13)$ resulted in a small variation in the number of trees monitored across the periods. Whenever possible, we also measured the DBH of fruit feeding trees and of trees in which agonistic interactions occurred.

We recorded fruit availability semiquantitatively (Fournier 1974), with a phenological scale of five scores: 0 (no fruit visible), 1 (1-25\% of the canopy containing fruit), 2 $(26-50 \%), 3(51-75 \%)$, and $4(76-100 \%)$. We used these data to calculate an index of fruit availability for each study period. First, we multiplied the phenological score of 
each tree by its DBH. Then, we calculated the mean value for each study period by dividing the sum of these products by the summed DBHs of the monitored trees. Lastly, we divided the mean value by 4 (the maximum Fournier availability) and multiplied it by 100 to scale our estimate of fruit availability at the forest level from 0 (no fruit available) to $100 \%$ (all trees with $>75 \%$ of the canopy bearing fruit). We used the DBH in our index because it is a good predictor of biomass and reproductive capacity (Chapman 1992; Strier 1989). This index ranged from $1.5 \%$ in the first sampling period at site A to a sixfold higher availability $(9.1 \%)$ in the eighth period for the same site. Given that we did not identify the trees, our index includes both plant species that serve as fruit sources for woolly monkeys and species that do not.

\section{Statistical Analysis}

We calculated the activity budget using the proportion method (sensu Clutton-Brock 1977). We first calculated the percentage of the sighted individuals in each scan that were engaged in each activity (and, when feeding, each food type). Then, we calculated the mean of the percentages for each activity or food type across scans for each day. We used the mean of the daily mean percentages to calculate the overall activity budget. We used only the scans with feeding records to calculate the degree of frugivory based on the same method. We calculated the degree of frugivory in each sampling period as the mean percentage of fruit eating during the three days of monitoring. We chose the proportion method given the high variation in the number of individuals recorded per scan sample to reduce the chance of overestimating the occurrence of more conspicuous behaviors and of underestimating less conspicuous ones.

We estimated the rates of agonism by dividing the number of aggressive interactions observed in each period by the corresponding number of hours of observation. We calculated an index of proximity for each period by dividing the number of records in which individuals had at least one nearest neighbor within a 5-m radius by the total number of samples in that period (following Stevenson 1998). This index varies from 0, when all individuals are $>5 \mathrm{~m}$ from one another throughout the study period, to 1 , when all monkeys are within a 5-m radius of at least another individual throughout the study period.

We compared the DBHs of the trees exploited as fruit sources by the woolly monkeys and of those where they interacted agonistically with the DBHs of the trees in the phenological monitoring via the Wilcoxon rank sum test. We found no significant differences between study sites in fruit availability (Wilcoxon rank sum test: $W=$ $51, P=0.970)$, degree of frugivory $(W=31, P=0.161)$, rates of agonism $(W=45, P=$ $0.739)$, proximity index $(W=63, P=0.344)$, or the size of the monitored trees $(W=44$, $P=0.829)$. Therefore, we analyzed the pooled data set to increase sample size and statistical power (e.g., Vogel and Janson 2007).

We employed a protocol for data exploration (as described in Benhadi-Marín 2018; Zuur et al. 2010) to identify extreme data points that could bias our analyses and avoid common statistical problems. We detected and excluded one extreme observation (second period of the site A) in the regression between fruit availability and degree of frugivory. This observation was an exceptional period in which the monkeys fed exclusively on a single Ficus sp. tree for the entire 3-day study period.

We tested whether fruit availability predicted degree of frugivory, and whether fruit availability and degree of frugivory predicted the rates of agonistic interactions and 
intragroup proximity using generalized linear mixed models (GLMMs) with a Gaussian distribution and identity link function in the glmmTMB package (Brooks et al. 2017). We used site as a random effect in all regression models to account for correlation among repeated measures from the same site (Bolker et al. 2009). We did not use rates of agonistic interactions or intragroup proximity as independent variables to avoid effects of multicollinearity. In our study, degree of frugivory was significantly correlated with both proximity $\left(P<0.05, r_{\mathrm{s}}=0.50\right)$ and agonism $\left(P<0.05, r_{\mathrm{s}}=0.53\right)$, which can cause inaccurate model parameterization and decrease statistical power even with lower levels of collinearity (see Graham 2003). For each hypothesis, we compared the full and null models using analysis of variance (ANOVA) with a chi-square test. We used degree of frugivory and fruit availability in an additive full model to test $\mathrm{H} 2$. We used fixed effects with an interaction term (i.e., degree of frugivory $\times$ fruit availability) in the full model to test $\mathrm{H} 3$. We also compared the additive and interaction models to test H3. We tested for a significant correlation between agonism and spacing (H4) using the Spearman rank correlation test. We tested all final models' performances by checking residual diagnostics using the DHARMa package (Hartig 2019). We used conditional and cross-sectional plots in the visreg package (Breheny and Burchett 2017) to visualize the interactive and conditional effects of each variable in the models. To identify the directionality of the interaction between degree of frugivory and fruit availability in predicting intragroup proximity, we classified the fruit availably indices into two categories: lower (when indices were below the median) and higher (when indices were above the median) fruit availability. Finally, given that we tested H3 by comparing the full and null models and by testing the significance of the interaction term, we did not perform a post hoc analysis to identify the individual effects of lower and higher fruit availability. We set a two-tailed level of significance of 0.05 in all tests and used the R 3.4 .3 software (R Core Team 2018) for all data processing and modeling.

\section{Ethical Note}

This research was approved by the Scientific Committee of the Faculdade de Biociências, Pontifícia Universidade Católica do Rio Grande do Sul (PUCRS), Porto Alegre, Brazil, under the registration number 7656 in October 2016. The research adhered to Brazilian legal requirements and consisted only of observations of freeliving animals without any physical interaction with the primates. The authors declare that they have no conflict of interest.

Data Availability The data sets generated during the current study are available from the corresponding author on reasonable request.

\section{Results}

The gray woolly monkeys traveled $37 \%$ of the time, fed $32 \%$, rested $26 \%$, socialized $4 \%$, and engaged in other behaviors $1 \%(N=3549$ records). Agonistic interactions accounted for only $17 \%$ of the social behaviors recorded via scan sampling. 


\section{Fruit Availability and Frugivory}

The diet of gray woollies consisted primarily of fruit $(65 \%)$, and was complemented with $11 \%$ of leaves, $8 \%$ of flowers, $9 \%$ of other plant items and $7 \%$ of prey $(N=1128$ records). The DBH of trees used as fruit patches differed significantly from the DBH of trees randomly selected for phenological monitoring $(W=4,538.5, P<0.001)$. The $\mathrm{DBH}$ of the former were nearly four times larger $($ mean $=83 \pm \mathrm{SD} 88 \mathrm{~cm}$, median $=59$ $\mathrm{cm}$, range $=13-569 \mathrm{~cm}, N=74)$ than that of the latter $($ mean $=23 \pm \mathrm{SD} 20 \mathrm{~cm}$, median $=17 \mathrm{~cm}$, range $=10-323 \mathrm{~cm}, N=600$ ). The full model performed significantly better than the null model (ANOVA: $\chi^{2}=9.7314, \mathrm{df}=1, P=0.002$ ) and as predicted based on $\mathrm{H} 1$, fruit availability significantly predicted the degree of frugivory $(Z=3.722, P=$ 0.0002; Fig. 2).

\section{Frugivory and Behavior}

Rates of agonistic interactions varied from 0.03 to 0.63 events per hour (mean $=0.25 \pm$ SD 0.16, median $=0.22$ ). Most agonistic interactions in which the context was identified (165 of 193 events $=85 \%$ ) occurred during feeding. The majority of these interactions (157 of 165 events $=95 \%$ ) involved threat displays, lunges, chases, or other physical contacts. The remaining agonistic interactions ( 8 cases $=5 \%)$ involved supplants or displacements. Of the agonistic interactions in feeding contexts, $88 \%(N=$ $129)$ occurred over fruit, $11 \%(N=16)$ over flowers and flower buds, and $1 \%(N=2)$ over leaves. Notably, agonistic interactions usually occurred in fruit patches that were significantly larger $(W=1221, P<0.001)$ by $36 \%$ on average (mean DBH $=113 \pm \mathrm{SD}$ $117 \mathrm{~cm}$, median $=65 \mathrm{~cm}$, range $=22-569 \mathrm{~cm}, N=34)$ than feeding fruit trees in general $($ mean $=83 \pm \mathrm{SD} 88 \mathrm{~cm}$, median $=59 \mathrm{~cm}$, range $=13-569 \mathrm{~cm}, N=74)$. The full model performed significantly better than the null model (ANOVA: $\chi^{2}=6.6867, \mathrm{df}$ $=2, P=0.035$ ), supporting $\mathrm{H} 2$. However, only the degree of frugivory was

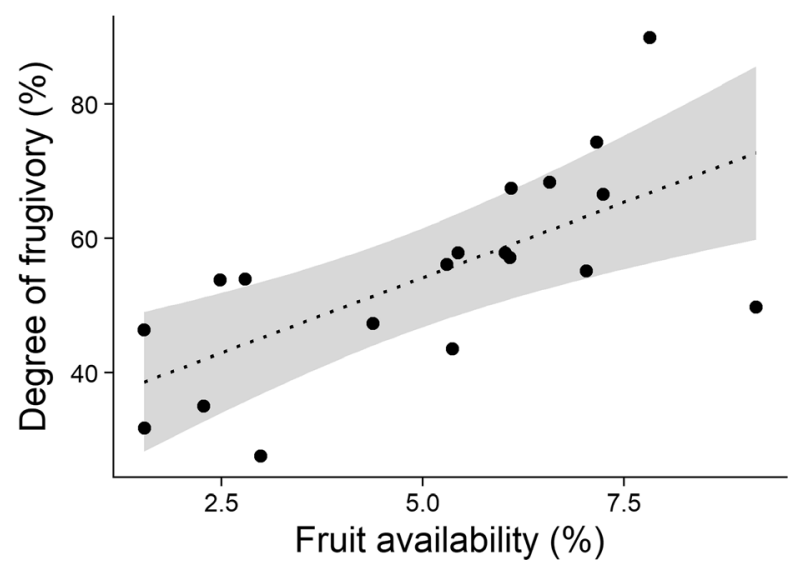

Fig. 2 Degree of frugivory of wild gray woolly monkeys in relation to overall fruit availability at two forest fragments in southwestern Brazilian Amazonia, Rondônia state, March to October 2017. Each point represents a sampling period. The lines represent predicted means derived from the generalized linear mixed model. The gray area represents the $95 \%$ confidence interval. 
significantly related to the rates of agonistic interactions in the full model (degree of frugivory: $Z=2.585, P=0.0097$; Fig. 3 ).

Woolly monkeys were within $5 \mathrm{~m}$ of at least one other individual in $50 \%$ of the 3549 records of spacing. The proximity index varied from 0.23 to 0.71 (mean $=0.48 \pm \mathrm{SD}$ 0.13 , median $=0.48$ ). The full model (with the interaction term) predicting intragroup proximity performed significantly better than the null and the additive models (ANOVA: $\chi^{2}=9.6482$, $\mathrm{df}=2, P=0.008$ and $\chi^{2}=6.7986$, $\mathrm{df}=1, P=0.009$, respectively), supporting $\mathrm{H} 3$. A significant interaction term $(Z=-2.959, P=0.0030)$ in the full model indicates that the association between degree of frugivory and intragroup proximity depended on the overall fruit availability (Fig. 4). Lastly, supporting H4, the proximity index and the rates of agonistic interactions were significantly correlated $\left(r_{\mathrm{s}}\right.$ $=0.45, P=0.049$ ) in a positive monotonic relationship.

\section{Discussion}

We found that gray woolly monkeys behaved as generalized opportunistic frugivores, increasing their consumption of fruit as fruit availability increased, as predicted by our first hypothesis. They resembled other woolly monkeys (Di Fiore 2004; Di Fiore and Rodman 2001; Gonzalez et al. 2016; Peres 1994a; Stevenson 2004), and other species of atelines, including northern muriquis (Strier 1991), black-faced black spider monkeys (Wallace 2008), and variegated spider monkeys (Ateles hybridus: Link et al. 2012). Their selection of large fruiting trees also resembled the pattern reported for other atelines, where large patches support larger feeding parties (Peres 1996; Strier 1989; Wallace 2008). However, although interindividual distance appears to reduce intragroup feeding competition in periods of fruit scarcity for muriquis and spider

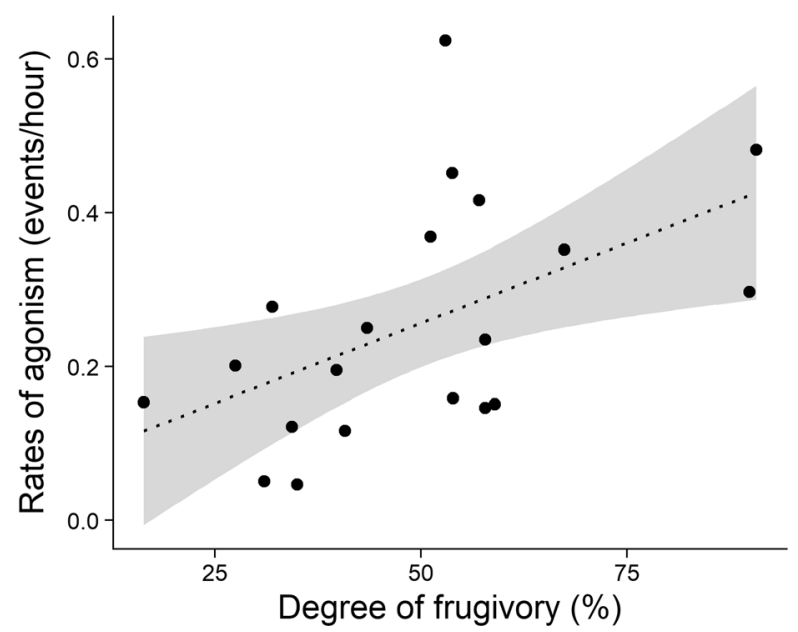

Fig. 3 Rates of agonistic interactions among wild gray woolly monkeys in relation to their degree of frugivory at two forest fragments in southwestern Brazilian Amazonia, Rondônia state, March to October 2017. Conditional plot is shown where partial residuals were plotted against the focal predictor (i.e., degree of frugivory) while controlling for fruit availability. Each point represents a sampling period. The lines represent predicted means derived from the generalized linear mixed model. The gray area represents the $95 \%$ confidence interval. 


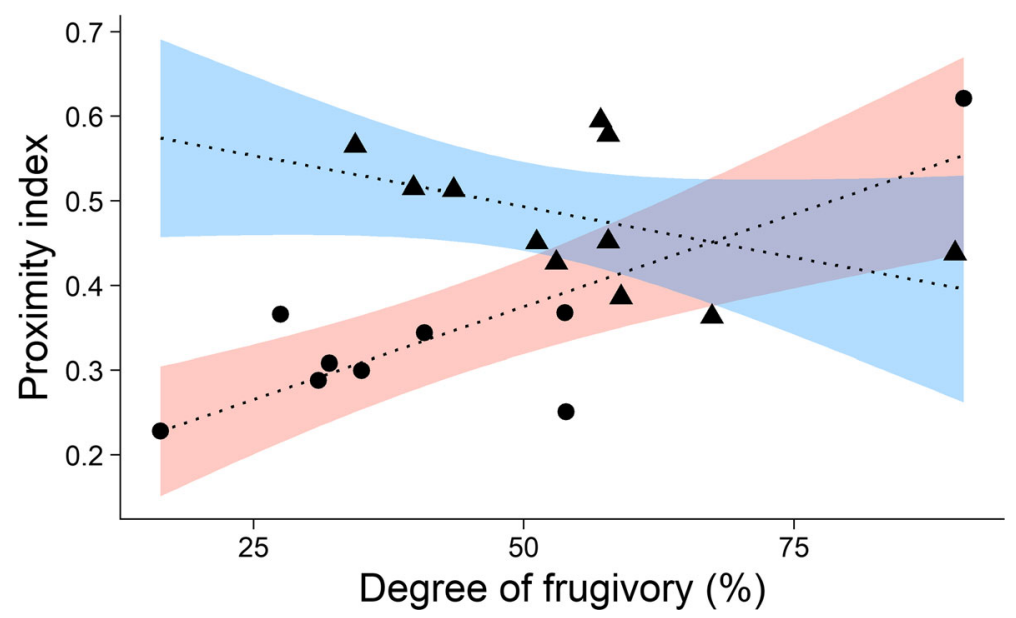

Fig. 4 Intragroup proximity in wild gray woolly monkeys in relation to their degree of frugivory during periods of lower and higher fruit availability at two forest fragments in southwestern Brazilian Amazonia, Rondônia state, March to October 2017. Cross-sectional plot is shown depicting the fit of a model with an interaction term between degree of frugivory and fruit availability. Each point represents a sampling period. The lines represent predicted means derived from the generalized linear mixed model. The overlaid red and blue bands represent the $95 \%$ confidence intervals for each category of fruit availability.

monkeys (e.g., Pinacho-Guendulain and Ramos-Fernández, 2017; Strier 1989; Symington 1990; Wallace 2008), this did not seem to be the case for the gray woolly monkeys in our study. The woolly monkeys' selection of large feeding patches allowed them to feed more closely together, but also created more opportunities for agonistic interactions, presumably in response to the increased proximity when feeding on fruit in periods of lower availability.

Fruits were the gray woolly monkeys' most contested resource. The positive monotonic relationship between rates of agonistic interactions and frugivory is compatible with a scenario of insufficient fruit availability to meet the needs of all group members. A similar monotonic relationship between agonism and frugivory was found in a study of common woolly monkeys during a complete annual cycle (Stevenson et al. 1994). The fission-fusion dynamics typically employed by ateline fruit specialists are thought to be adaptive in reducing intraspecific competition when fruit is seasonally scarce and distributed in discrete, defensible patches (e.g., Pinacho-Guendulain and Ramos-Fernández 2017). However, as predicted, the woolly monkeys in our study exhibited higher rates of agonistic interactions (H2) and closer proximity (H3) as the degree of frugivory increased in periods of lower fruit availability. These findings are consistent with the behavior of primates with more generalized diets (e.g., blond capuchin monkeys: Lins and Ferreira 2019; mountain gorillas: Robbins 2008; whitefaced capuchin monkeys: Vogel and Janson 2007). In these species, switching to alternative food resources such as herbaceous vegetation or arthropods can mitigate feeding competition (e.g., Robbins 2008; Stevenson et al. 1994). For example, common woolly monkeys excluded from fruiting trees may forage for arthropod prey, an alternative resource highly consumed in periods of high fruit availability (Fonseca et al. 
2019; Stevenson et al. 1994). Therefore, the consumption of arthropods can buffer the negative effects of aggressive displacement from fruiting trees (Stevenson et al. 1994; Stevenson and Castellanos 2000). This foraging strategy may explain the small and cohesive groups of yellow-tailed woolly monkeys (Lagothrix flavicauda: Shanee 2014a) and common woolly monkeys (Stevenson et al. 1994). Groups of these species were reported to devote, respectively, up to $19 \%$ and $23 \%$ of their feeding time to arthropod consumption (Shanee 2014a; Stevenson et al. 1994).

We found that fruit availability, when controlled for degree of frugivory, was not a statistically significant predictor of the rates of agonistic interactions in the full model. The lack of information on the identity of fruit species and the characteristics of the exploited fruiting trees (e.g., fruit size, fruit density, and tree density) in our fruit availability index may, at least partially, explain this finding. Additionally, agonistic interactions in our study groups usually occurred in fruit patches that were, on average, $36 \%$ larger than feeding fruit trees in general, and nearly 500\% larger than the trees randomly selected for phenological monitoring. Studies monitoring taxonomically identified key food species (e.g., contributing $>20 \%$ to the diet), such as those conducted with other atelids (Geoffroy's spider monkeys, Ateles geoffroyi: PinachoGuendulain and Ramos-Fernández 2017), can improve our understanding of intragroup feeding competition in woolly monkeys.

Our study groups did not show high fission-fusion dynamics, as seen in spider monkeys, but neither did they show strict cohesion, as seen in other populations of common woolly monkeys (Di Fiore and Campbell 2007; Stevenson et al. 1994) and yellow-tailed woolly monkeys (Shanee 2014b). The overall spatial cohesion of the study woolly monkeys was low compared to the common woolly monkeys from Tinigua National Park (Stevenson et al. 1994), as individuals had no nearest neighbor within a 5-m radius in half of the behavioral records. Subgroups maintained contact via frequent vocal exchange, as reported for another population of gray woolly monkeys (Peres 1996), and northern muriquis (Arnedo et al. 2010). The large, diffuse groups of gray woolly monkeys can be advantageous in interspecifc competition for resources. We observed gray woolly monkeys acting aggressively toward other primates often when they were coexploiting fruiting trees (TC pers. obs.), unlike in previous studies with this species (Haugaasen and Peres 2009).

Low predation pressure is also likely to reduce intragroup proximity by relaxing the benefits of social cohesion (Boinski et al. 2000). The absence of significant predation risk may apply especially to adult male gray woolly monkeys, which may weigh up to $10 \mathrm{~kg}$ (Peres 1994b). However, even infrequent predation can be a strong selective force for large-bodied Atelidae (see Matsuda and Izawa 2008; Quintino and BiccaMarques 2013), particularly for the more vulnerable smaller adult females and immature individuals. The only published predation on woolly monkeys refers to an individual of unknown age and sex captured by a black-and-chestnut eagle (Spizaetus isidori: Lehman 1959 apud Ferrari 2009). Nonetheless, despite the presence of three large potential predators (jaguars, Panthera onca; red-tailed boas, Boa constrictor; and harpy eagles, Harpya harpya) in the study sites (TC pers. obs.), we did not observe any predation attempts during the study. Particularly in the case of pumas and jaguars, we cannot discard the influence of the observer's presence on the lack of daytime predation attempts, as previously suggested for adult spider monkeys and muriquis (Matsuda and Izawa, 2008; Tabacow et al. 2009). 
In sum, given that the degree of frugivory when controlled for, or when interacting with, fruit availability predicted the rates of agonistic interactions and intragroup proximity and that these variables covaried positively, we suggest that competition for fruit is an important modulator of woolly monkey social dynamics. Unlike other atelines (Stevenson et al. 2015; Strier 1989), the study subjects did not avoid agonistic competition over fruit by decreasing intragroup proximity, since feeding closely in a fruit patch created more opportunities for agonistic interactions, especially in periods of lower fruit availability. Conversely, as the degree of frugivory increased, they exhibited greater interindividual distances and consequently lower rates of agonism, consistent with lower levels of intragroup feeding competition in periods of higher fruit availability.

Future studies should assess how factors that affect feeding competition and social dynamics in other primates, such as fruit feeding bout length and number of adult males and females in feeding parties (Strier 1989; Vogel and Janson 2007), influence the predictive power of models of woolly monkey foraging. These studies should aim to identify and accurately measure fruit size and density within the canopies and the availability of alternative resources such as flowers and arthropod prey. They should also examine how the combined effect of the availability of these resources, especially fruit and arthropod prey, influence food intake (e.g., Fonseca et al. 2019) and, consequently, the frequency of scramble and contest competition for food in light of socioecological models.

Acknowledgments TC would like to express sincere thanks to all the local landowners who kindly allowed data collection in their rural properties. This goes especially to Seu Lourival, who was the main responsible for the protection of one of the study populations and recently passed away from complications of COVID-19. TC also deeply thanks Doriangela Diogo Davila da Silva and Anézio Ferreira da Silva for their hospitality, logistical support, and help during field campaigns. We express our sincere thanks to the two anonymous reviewers and to Dr. Joanna $\mathrm{M}$. Setchell for their comments and suggestions that greatly improved our manuscript. We also thank Anamelia S. Jesus for her assistance with map figure development and Italo Mourthe and Pablo Stevenson for essential comments regarding theory and methods of this research. JCBM acknowledges the Brazilian National Council for Scientific and Technological Development/CNPq for research fellowships (PQ 1C No. 303306/2013-0 and 304475/2018-1). This study was financed in part by the Coordenação de Aperfeiçoamento de Pessoal de Nível Superior - Brasil (CAPES) - Finance Code 001.

Author Contributions Contributions to the early planning of the study were made by TC and JCBM. TC and JCBM developed the overall research framework and designed the methodology. All data were collected by TC, who also performed all the statistical analyses. TC, KBS, and JCBM led the writing of the manuscript. All authors gave final revision and approval for publication and are accountable for all aspects of the work.

\section{References}

Altmann, J. (1974). Observational study of behavior: Sampling methods. Behaviour, 49, 227-267.

Arnedo, L. F., Mendes, F. D., \& Strier, K. B. (2010). Sex differences in vocal patterns in the northern muriqui (Brachyteles hypoxanthus). American Journal of Primatology, 72, 122-128.

Aureli, F., Schaffner, C. M., Boesch, C., Bearder, S. K., Call, J., Chapman, C. A., Connor, R., Di Fiore, A., Dunbar, R. I. M., Henzi, S. P., Holekamp, K., Korstjens, A. H., Layton, R., Lee, P., Lehmann, J., Manson, J. H., Ramos-Fernandez, G., Strier, K. B., \& van Schaik, C. P. (2008). Fission-fusion dynamics: New research frameworks. Current Anthropology, 49, 627-654. 
Benhadi-Marín, J. (2018). A conceptual framework to deal with outliers in ecology. Biodiversity and Conservation, 27, 3295-3300.

Bernstein, I. (2007). Social mechanisms in the control of primate aggression. In C. J. Campbell, A. Fuentes, K. C. Mackinnon, M. Panger, \& S. K. Bearder (Eds.), Primates in perspective (pp. 562-571). New York: Oxford University Press.

Boinski, S., Treves, A., \& Chapman, C. A. (2000). A critical evaluation of the influence of predators on primates: effects on group travel. In S. Boinski \& P. Garber (Eds.), On the move: How and why animals travel in groups (pp. 43-72). Chicago: University of Chicago Press.

Bolker, B. M., Brooks, M. E., Clark, C. J., Geange, S. W., Poulsen, J. R., et al (2009). Generalized linear mixed models: A practical guide for ecology and evolution. Trends in Ecology and Evolution, 24, 127135.

Breheny, P., \& Burchett, W. (2017). Visualization of regression models using visreg. The R Journal, 9, 56-71.

Brooks, M. E., Kristensen, K., van Benthem, K. J., Magnusson, A., Berg, C. W., et al (2017). glmmTMB balances speed and flexibility among packages for zero-inflated generalized linear mixed modeling. The $R$ Journal, 9, 378-400.

Cavalcante, T., Gusmão, A. C., \& Ferrari, S. F. (2018). Unexpected diversity: The potential role of privatelyowned forest remnants in the conservation of the primates of the highly-impacted Rondônia center of endemism, southwestern Brazilian Amazonia. Neotropical Primates, 24, 82-85.

Cavalcante, T., Simões, P. I., \& Mourthe, I. (2019). Predation of Boana boans (Anura, Hylidae) by an opportunistic frugivorous primate. Acta Amazonica, 49, 307-310.

Chapman, C. A. (1992). Estimators of fruit abundance of tropical trees. Biotropica, 24, 527-531.

Chapman, C. A., Wrangham, R., \& Chapman, L. J. (1995). Ecological constraints on group size: An analysis of spider monkey and chimpanzee subgroups. Behavioral Ecology and Sociobiology, 36, 59-70.

Clutton-Brock, T. (1977). Appendix I: Methodology and measurement. In T. H. Clutton-Brock (Ed.), Primate ecology: Studies of foraging and ranging behaviour in lemurs, monkeys, and apes (pp. 585-590). London: Academic Press.

Defler, T. R. (1996). Aspects of the ranging pattern in a group of wild woolly monkeys (Lagothrix lagothricha). American Journal of Primatology, 38, 289-302.

Di Fiore, A. (2003). Ranging behavior and foraging ecology of lowland woolly monkeys (Lagothrix lagotricha poeppigii) in Yasuni National Park, Ecuador. American Journal of Primatology, 59, 47-66.

Di Fiore, A. (2004). Diet and feeding ecology of woolly monkeys in a western Amazonian rain forest. International Journal of Primatology, 25, 767-801.

Di Fiore, A., \& Campbell, C. J. (2007). The Atelines: Variation in ecology, behavior and social organization. In C. J. Campbell, A. Fuentes, K. C. MacKinnon, M. Panger, \& S. K. Bearder (Eds.), Primates in perspective (pp. 155-185). New York: Oxford University Press.

Di Fiore, A., \& Fleischer, R. C. (2005). Social behavior, reproductive strategies, and population genetic structure of Lagothrix poeppigii. International Journal of Primatology, 26, 1137-1173.

Di Fiore, A., \& Rodman, P. S. (2001). Time allocation patterns of lowland woolly monkeys (Lagothrix lagotricha poeppigii) in a Neotropical terra firma forest. International Journal of Primatology, 22, 449480.

Fairbanks, L. A., \& Bird, J. (1978). Ecological correlates of interindividual distance in the St. Kitts vervet (Cercopithecus aethiops sabaeus). Primates, 19, 605-614.

Ferrari, S. F. (2009). Predation risk and antipredator strategies. In P. Garber, A. Estrada, J. C. Bicca-Marques, E. W. Heymann, \& K. B. Strier (Eds.), South American Primates: Comparative perspectives in the study of behaviour, ecology and conservation (pp. 251-278). New York: Springer.

Fonseca, M. L., Cruz, D. M., Rojas, D. C. A., Crespo, J. P., \& Stevenson, P. R. (2019). Influence of arthropod and fruit abundance on the dietary composition of highland Colombian woolly monkeys (Lagothrix lagotricha lugens). Folia Primatologica, 90, 240-257.

Fournier, L. A. (1974). Un método cuantitativo para la medición de características fenológicas en árboles. Turrialba, 24, 422-423.

Gentry, A. H. (1982). Patterns of neotropical plant species diversity. Evolutionary Biology, 15, 1-85.

Gonzalez, M., Clavijo, L., Betancur, J., \& Stevenson, P. R. (2016). Fruits eaten by woolly monkeys (Lagothrix lagothricha) at local and regional scales. Primates, 57, 241-251.

Graham, M. H. (2003). Confronting multicollinearity in ecological multiple regression. Ecology, 84, 28092815.

Hartig, F. (2019). DHARMa: Residual diagnostics for hierarchical (MultiLevel/Mixed) regression models. Retrieved from http://florianhartig.github.io/DHARMa/

Haugaasen, T., \& Peres, C. A. (2009). Interspecific primate associations in Amazonian flooded and unflooded forests. Primates, 50, 239-251. 
Isbell, L. A. (1991). Contest and scramble competition: Patterns of female aggression and ranging behavior among primates. Behavioral Ecology, 2, 143-155.

Isbell, L. A., Pruetz, J. D., \& Young, T. P. (1998). Movements of vervets (Cercopithecus aethiops) and patas monkeys (Erythrocebus patas) as estimators of food resource size, density, and distribution. Behavioral Ecology and Sociobiology, 42, 123-133.

Iwanaga, S., \& Ferrari, S. F. (2001). Party size and diet of syntopic atelids (Ateles chamek and Lagothrix cana) in southwestern Brazilian Amazonia. Folia Primatologica, 72, 217-227.

Link, A., Galvis, N., Marquez, M., Guerrero, J., Solano, C., \& Stevenson, P. R. (2012). Diet of the critically endangered brown spider monkey (Ateles hybridus) in an inter-Andean lowland rainforest in Colombia. American Journal of Primatology, 74, 1097-1105.

Lins, P. G. A. S., \& Ferreira, R. G. (2019). Competition during sugarcane crop raiding by blond capuchin monkeys (Sapajus flavius). Primates, 60, 81-91.

Magnusson, W. E., Lima, A. P., Luizão, R., Luizão, F., Costa, F. R., et al (2005). RAPELD: A modification of the Gentry method for biodiversity surveys in long-term ecological research sites. Biota Neotropica, 5, 19-24.

Majolo, B., Vizioli, A. B., \& Schino, G. (2008). Costs and benefits of group living in primates: Group size effects on behaviour and demography. Animal Behaviour, 76, 1235-1247.

Matsuda, I., \& Izawa, K. (2008). Predation of wild spider monkeys at La Macarena, Colombia. Primates, 49, 65-68.

Norconk, M. A., \& Kinzey, W. G. (1994). Challenge of neotropical frugivory: Travel patterns of spider monkeys and bearded sakis. American Journal of Primatology, 34, 171-183.

Pereira, M. E. (1988). Agonistic interactions of juvenile savanna baboons. Ethology, 79, 195-217.

Peres, C. A. (1994a). Diet and feeding ecology of gray woolly monkeys (Lagothrix lagotricha cana) in central Amazonia: comparisons with other atelines. International Journal of Primatology, 15, 333-370.

Peres, C. A. (1994b). Which are the largest New World monkeys? Journal of Human Evolution, 26, $245-249$.

Peres, C. A. (1996). Use of space, spatial group structure, and foraging group size of gray woolly monkeys (Lagothrix lagotricha cana) at Urucu, Brazil. In M. A. Norconk, A. L. Rosenberger, \& P. A. Garber (Eds.), Adaptative radiation of Neotropical primates (pp. 467-488). New York: Plenum Press.

Pinacho-Guendulain, B., \& Ramos-Fernández, G. (2017). Influence of fruit availability on the fission-fusion dynamics of spider monkeys (Ateles geoffroyi). International Journal of Primatology, 38, 466-484.

Quintino, E. P., \& Bicca-Marques, J. C. (2013). Predation of Alouatta puruensis by Boa constrictor. Primates, $54,325-330$

R Core Team (2018). R: A language and environment for statistical computing. R Foundation for Statistical Computing.

Ramirez, M. (1988). The woolly monkeys, genus Lagothrix. In R. A. Mittermeier, A. B. Rylands, A. F. Coimbra-Filho, \& G. A. B. da Fonseca (Eds.), Ecology and behavior of Neotropical primates (pp. 539575). Washington, DC: World Wildlife Fund.

Robbins, M. M. (2008). Feeding competition and agonistic relationships among Bwindi Gorilla beringei. International Journal of Primatology, 29, 999-1018.

SEDAM (2012). Secretaria de Estado do Desenvolvimento Ambiental. Boletim climatológico de Rondônia2010, 12, 1-34.

Shanee, S. (2014a). Ranging behaviour, daily path lengths, diet and habitat use of yellow-tailed woolly monkeys (Lagothrix flavicauda) at La Esperanza, Peru. In T. R. Defler \& P. R. Stevenson (Eds.), The woolly monkey: Behavior, ecology, systematics, and captive research (pp. 167-185). New York: Springer.

Shanee, S. (2014b). Yellow-tailed woolly monkey (Lagothrix flavicauda) proximal spacing and forest strata use in La Esperanza, Peru. Primates, 55, 515-523.

Snaith, T. V., \& Chapman, C. A. (2007). Primate group size and interpreting socioecological models: Do folivores really play by different rules? Evolutionary Anthropology, 16, 94-106.

Stevenson, P. R. (1998). Proximal spacing between individuals in a group of woolly monkeys (Lagothrix lagotricha) in Tinigua National Park, Colombia. International Journal of Primatology, 19, 299-311.

Stevenson, P. R. (2004). Fruit choice by woolly monkeys in Tinigua National Park, Colombia. International Journal of Primatology, 25, 367-381.

Stevenson, P. R., \& Castellanos, M. C. (2000). Feeding rates and daily path range of the Colombian woolly monkeys as evidence for between- and within-group competition. Folia Primatologica, 71, 399-408.

Stevenson, P. R., Quinones, M. J., \& Ahumada, J. A. (1994). Ecological strategies of woolly monkeys (Lagothrix lagotricha) at Tinigua National Park, Colombia. American Journal of Primatology, 32, 123140 . 
Stevenson, P. R., Quinones, M. J., \& Ahumada, J. A. (1998). Effects of fruit patch availability on feeding subgroup size and spacing patterns in four primate species at Tinigua National Park, Colombia. International Journal of Primatology, 19, 313-324.

Stevenson, P. R., Zárate, D. A., Ramírez, M. A., \& Henao-Díaz, L. F. (2015). Social interactions and proximal spacing in woolly monkeys: Lonely females looking for male friends. In T. Furuichi, F. Aureli, \& J. Yamagiwa (Eds.), Dispersing primate females: Life history and social strategies in male-philopatric species (pp. 45-71). Primatology Monographs. New York: Springer.

Strier, K. B. (1989). Effects of patch size on feeding associations in muriquis (Brachyteles arachnoides). Folia Primatologica, 52, 70-77.

Strier, K. B. (1991). Diet in one group of woolly spider monkeys, or muriquis (Brachyteles arachnoides). American Journal of Primatology, 23, 113-126.

Su, H. H., \& Birky, W. A. (2007). Within-group female-female agonistic interactions in taiwanese macaques (Macaca cyclopis). American Journal of Primatology, 69, 199-211.

Symington, M. M. (1990). Fission-fusion social organization in Ateles and Pan. International Journal of Primatology, $11,47-61$.

Tabacow, F. P., Mendes, S. L., \& Strier, K. B. (2009). Spread of a terrestrial tradition in an arboreal primate. American Anthropologist, 111, 238-249.

Vogel, E., \& Janson, C. (2007). Predicting the frequency of food-related agonism in white-faced capuchin monkeys (Cebus capucinus), using a novel focal-tree method. American Journal of Primatology, 69, 533-550.

Wallace, R. B. (2008). The influence of feeding patch size and relative fruit density on the foraging behavior of the black spider monkey Ateles chamek. Biotropica, 40, 501-506.

Wrangham, R. (1980). An ecological model of female-bonded primate groups. Behaviour, 75, 262-300.

Zuur, A. F., Ieno, E. N., \& Elphick, C. S. (2010). A protocol for data exploration to avoid common statistical problems. Methods in Ecology and Evolution, 1, 3-14.

\section{Affiliations}

\section{Thiago Cavalcante ${ }^{1,2}$ - Karen B. Strier ${ }^{3}$. Júlio César Bicca-Marques ${ }^{2}$}

1 Programa de Pós-Graduação em Ecologia, Instituto Nacional de Pesquisas da Amazônia, INPA, Manaus, Amazonas, Brazil

2 Laboratório de Primatologia, Escola de Ciências da Saúde e da Vida, Pontifícia Universidade Católica do Rio Grande do Sul, PUCRS, Porto Alegre, Brazil

3 Department of Anthropology, University of Wisconsin-Madison, Madison, Wisconsin, USA 